\title{
Application of leukocyte subsets and sperm DNA fragment rate in infertile men with asymptomatic infection of genital tract
}

\author{
Kang-Sheng Liu ${ }^{1}$, Xiao-Dong $\mathrm{Mao}^{2}$, Feng Pan ${ }^{3}$, Ya-Jun Chen ${ }^{1}$ \\ ${ }^{1}$ Department of Clinical Laboratory, Women's Hospital of Nanjing Medical University, Nanjing Maternity and Child Health Care Hospital, \\ Nanjing, China; ${ }^{2}$ Department of Endocrinology, Affiliated Hospital of Integrated Traditional Chinese and Western Medicine, Nanjing University \\ of Chinese Medicine, Nanjing, China; ${ }^{3}$ Department of Andrology, State Key Laboratory of Reproductive Medicine, Women's Hospital of Nanjing \\ Medical University, Nanjing Maternity and Child Health Care Hospital, Nanjing, China \\ Contributions: (I) Conception and design: KS Liu; (II) Administrative support: XD Mao; (III) Provision of study materials or patients: KS Liu, F Pan; \\ (IV) Collection and assembly of data: KS Liu, YJ Chen; (V) Data analysis and interpretation: KS Liu, YJ Chen; (VI) Manuscript writing: All authors; \\ (VII) Final approval of manuscript: All authors. \\ Correspondence to: Prof. Ya-Jun Chen. Department of Clinical Laboratory, Women's Hospital of Nanjing Medical University, Nanjing Maternity and \\ Child Health Care Hospital, Nanjing 210029, China. Email: fyyajunchen2016@163.com.
}

Background: About $15 \%$ of male infertility is due to genital tract infection and inflammation, some of them have no clinical symptoms, but manifested as leukocytospermia (LCS). Leukopenia will lead to functional impairment of male sperm and integrity damage of sperm morphology. A large amount of reactive oxygen species (ROS) produced by leukocytes can damage sperm nuclear DNA. The aim of this study was to investigate the correlation between leukocyte subsets and sperm DNA fragmentation rate in semen of infertile men with asymptomatic infection of genital tract.

Methods: One hundred and eight cases of infertile men were enrolled, who were admitted to our hospital from May 2016 to September 2018, and all had genital tract infections. After routine sperm analysis, realtime PCR was performed for detecting the infection of chlamydia trachoma (CT) and Ureaplasma urealyticum $(U U)$. Furthermore, total leukocyte count in semen was evaluated by detection of CD45 molecules using immunocytochemistry. Flow cytometry was used for subset analysis, monocyte/macrophages were evaluated by CD14, and activated macrophages were evaluated by HLA-DR antigen. Sperm DNA fragmentation index (DFI) were evaluated by SCD method and 8-hydroxydeoxyguanosine (8-OHdG) expression were evaluated by chromatin diffusion method and TUNEL method; the correlation analysis was conducted between semen leukocyte subsets, sperm DNA fragment rate and conventional semen parameters.

Results: There was a significant correlation among the concentrations of cells expressing HLA-DR antigen and those expressing CD14 $(\mathrm{P}<0.01)$, but the concentrations of differential leukocyte subsets all had no significant correlation with sperm DFI, the percentage of 8-OHdG-expressing cells and routine semen parameters. The percentage of 8-OHdG-expressing sperm was positively correlated with the percentage of sperm fragments $(\mathrm{r}=0.42, \mathrm{P}<0.01)$, and negatively correlated with sperm concentration $(\mathrm{r}=-0.32, \mathrm{P}<0.01)$. After adjustment for possible confounders including age, abstinence time and smoking, the percentage of $8-\mathrm{OHdG}$-expressing sperms independently associated with sperm concentration $(\beta=-0.30 ; \mathrm{P}=0.006)$ and DFI $(\beta=0.180, \mathrm{P}=0.06)$.

Conclusions: Among infertile men with genital tract infection, the sperm DFI is associated with decreased semen quality and not the concentration of differential leukocyte subsets.

Keywords: Leukocyte subset; genital tract infection; infertile men; 8-hydroxydeoxyguanosine (8-OHdG)

Submitted Dec 09, 2019. Accepted for publication Aug 04, 2020.

doi: 10.21037/apm-19-597

View this article at: http://dx.doi.org/10.21037/apm-19-597 


\section{Introduction}

Leukocytospermia (LCS) or pyospermia is often defined as human semen with more than one million leukocytes in $1 \mathrm{~mL}$ volume, and has been proposed as an indicator for genital tract infection and inflammation (1). Although not all infections have elevated levels of semen leukocytes, and other reported causes also lead to LCS $(2,3)$, some prospective studies have shown that LCS alone exert adverse effects on the function and morphology integrity of sperms (3-7). Moubasher et al. (1) showed that LCS has a high correlation with sperm deformity index (SDI), the destruction of the acrosome, the missing of middle segment and the abnormality of tail. Immunocytochemistry uses monoclonal antibodies to specifically bind to leukocyte surface antigens. It is the gold standard for accurate assessment of leukocyte concentration in clinical studies.

Until now broad-spectrum antibiotics and antioxidants have been routinely used to treat male infertility caused by LCS, for they can eliminate infection and reduce the reactive oxygen species (ROS) released by leukocytes during inflammatory reactions $(8,9)$. Leukocytes activated by inflammation produce 100 times more ROS than unactivated leukocytes (10). Inconsistent results were obtained about the affection of inflammation on sperm concentration, activity and other routine parameters, but inflammation would damage sperm DNA $(3,11,12)$. Immature sperm, especially those with deformed head and cytoplasmic retention are also the main sources of ROS (13). Mature hindrance of sperm leads to an accumulation of enzymes including glucose-6-phosphate dehydrogenase (G6PD) and nicotinamide adenine dinucleotide phosphate (NADPH) oxidase, G6PD-derived NADPH is oxidized by NADPH oxidase, and produce large amounts of ROS (14-16). When sperm nuclear DNA undergoes oxidative stress, unsaturated fatty acids are enriched in sperm plasma membrane, which can react with ROS scavenging enzymes, thus destroying the fluidity and integrity of the sperm plasma membrane, and ultimately leading to damage of sperm nuclear DNA (16). Sperm mitochondrial DNA has poor self-healing ability and is sensitive to oxidative stress, for lacking protection of protamine and DNAbinding proteins, so its DNA damage is more common (16-19). Wright et al. (20) proved the semen contained higher concentration of $\mathrm{H}_{2} \mathrm{O}_{2}$ when more sperms of high DNA damage in it. 8-hydroxydeoxyguanosine (8-OHdG) is the most suitable biomarker for detecting oxidative damage of DNA caused by ROS (21). It was produced through a large number of ROS directly attacking guanine or hydroxyl radicals attacking the C-8 on deoxyguanosine in DNA $(15,22)$. The sperm DNA fragment rate measured by TUNEL or chromatin diffusion method is highly correlated with the level of $8-\mathrm{OHdG}$, which suggesting a relationship between oxidative stress and sperm DNA fragments rate $(23,24)$. As $8-\mathrm{OHdG}$ can be detected in single sperm cell, detection of $8-\mathrm{OHdG}$ is beneficial to analyzing the correlation between leukocyte levels and sperm DNA damage in semen.

In this study, 108 infertile men with genital tract infections were selected as subjects. Immunocytochemistry and flow cytometry were used to determinate $8-\mathrm{OHdG}$ level, distribution of leukocyte subsets respectively, so to explore the relationship between them.

\section{Methods}

\section{Participants}

One hundred and eight infertile men were enrolled in this study, all visited our Andrology Laboratory of Reproductive Medicine Center from May 2016 to September 2018, and were 30-50 (average age 33.6 \pm 10.1 ) years old. Inclusion criteria: All patients had no colds and history of special medications in the past 3 months (such as taking antioxidants and drugs affecting the immune systems), excluding patients with abnormal testicular, epididymis, and vas deferens, azoospermia cases were also excluded. The study was approved by the Ethics Committee of Women's Hospital of Nanjing Medical University (No. 20180332) and conducted in accordance with the Declaration of Helsinki (as revised in 2013). All the patients provided the written informed consent.

\section{Sample preparation and routine semen analysis}

Semen samples were obtained through masturbation after 3-5 days of abstinence and placed into sterile plastic containers, then put in a $37^{\circ} \mathrm{C}$ incubator. After liquefaction, partial semen samples were taken in a sterile tube for later detection of CT-DNA and UU-DNA. Semen analysis was performed according to the fifth edition of the World Health Organization's "Standard for the Inspection and Treatment of Male Infertility". The routine semen analysis (such as sperm concentration, total motile sperm and percentage of progressively motile sperm, etc.) was performed with a semen quality detection system (WLJY- 
9000, Beijing Weili New century Science \& Tech Dev. Co. Ltd.) and matching reagents. Main technical parameters are as follows. Image acquisition frame: low and middle sperm concentration collected at $20 \mathrm{~Hz}$, and high sperm concentration at $7 \mathrm{~Hz}$; acquisition interval: $3 \mathrm{~ms}$; maximum sperm motile velocity: $200 \mu \mathrm{m} \mathrm{s}^{-1}$; area range of spermatozoa head detected at $7-60 \mu^{2}$. Sperm motility was assessed by straight line velocity (VSL). Features of system software: grayscale thresholds were set to collect spermatozoa and exclude nonsperm granules. According to the threshold set for sperm analysis, sperm motile images were collected and analyzed. The sperm morphology analysis was performed by modified Pap test.

\section{Normal parameters (25)}

(I) Semen volume $\geq 1.5 \mathrm{~mL}$; $\mathrm{pH} \geq 7.2$; liquefaction time $<60 \mathrm{~min}$; total motile spermatozoa $\geq 39 \times 10^{6} /$ an entire ejaculate; sperm count $\geq 15 \times 10^{6} / \mathrm{mL}$; motility $\geq 40 \%$; vitality $\geq 50 \%$; morphology: proportion of sperms with normal morphology $\geq 4 \%$.

(II) Sperm with normal forward movement: sperms of grade $(A+B) \geq 32 \%$, or sperms of grade $A \geq 25 \%$.

\section{Diagnostic criteria of asthenozoospermia (25)}

Mild: $30 \%$ to $50 \%$ sperms at grade (A + B), or $10 \%$ to $25 \%$ sperms at grade A.

Moderate: $30 \%$ to $50 \%$ sperms at grade $(\mathrm{A}+\mathrm{B})$, and sperms of grade $\mathrm{A} \leq 10 \%$.

Severe: Sperms of grade $(B+C) \leq 30 \%$, and absence of grade A sperms.

\section{CT-DNA and UU-DNA tests}

Real-time quantitative PCR was performed to determine NG-DNA, CT-DNA, and UU-DNA levels by using commercially available kits (DAAN Gene, Guangzhou, China) and cycler Prism 7500 (ABI, USA), the PCR program was carried out as follows: $93^{\circ} \mathrm{C}$ for $2 \mathrm{~min}, 1$ cycle; $93{ }^{\circ} \mathrm{C}$ for $45 \mathrm{~s}$ and $55{ }^{\circ} \mathrm{C}$ for $60 \mathrm{~s}, 10$ cycles; $93{ }^{\circ} \mathrm{C}$ for $30 \mathrm{~s}$ and $55{ }^{\circ} \mathrm{C}$ for $45 \mathrm{~s}, 30$ cycles. For each experiment, the standard curve was constructed using the standard in the kit. Negative and blank control groups were set. The quantified data was software-analyzed. The level of pathogen $\geq 500 \mathrm{copy} / \mathrm{mL}$ was considered positive, $<500 \mathrm{copy} / \mathrm{mL}$ was negative.

\section{Determination of semen leukocytes by immunocytochemistry assessment of sperm 8-OHdG}

According to WHO recommendations (World Health Organization, 2010), round cells were recognized as leukocytes by detecting the pan-leukocyte CD45 antigen with a monoclonal anti-CD45 antibody and an avidinbiotin immunoperoxidase staining. The concentration of leukocytes $\left(10^{6} / \mathrm{mL}\right)$ in semen was obtained by multiplying the percentage of CD45-stained round cells. After that, each sample was washed twice $(400 \mathrm{~g}$ for $10 \mathrm{~min}$ ) in PBS containing $0.1 \%$ human serum albumin (HSA) and divided into three aliquots for subsequent flow cytometric assessment of leukocyte subsets, sperm DNA fragmentation, and sperm 8-OHdG expressions, respectively, as described below.

The generation of the oxidized base adduct, $8-\mathrm{OHdG}$ was detected as a biomarker for oxidative genomic damage (26). For the assay, samples were washed twice in PBS, the pellet was then resuspended in dithiothreitol $(2 \mathrm{mM})$ and incubated at $37^{\circ} \mathrm{C}$ for $45 \mathrm{~min}$. After centrifugation at 600 for $5 \mathrm{~min}$, samples were fixed in paraformaldehyde (4\% in PBS for 15 min at $4{ }^{\circ} \mathrm{C}$ ).

Fixed cells were washed and split into two aliquots subsequently incubated $\left(1 \mathrm{~h}\right.$ at $\left.37{ }^{\circ} \mathrm{C}\right)$ in $100 \mu \mathrm{L} 0.1 \%$ sodium citrate $/ 0.1 \%$ Triton $\mathrm{X}-100$ containing a mouse anti8-OHdG monoclonal antibody (Santa Cruz Biotechnology), diluted in a PBS solution with $2 \%$ HSA (test sample, $2 \mu \mathrm{g} / \mathrm{mL}$ ) or a mouse IgG2a (isotype control, $2 \mu \mathrm{g} / \mathrm{mL}$ ). After washing twice, spermatozoa were incubated in the dark ( $1 \mathrm{~h}$ at $\mathrm{RT}$ ) with a FITC-conjugated goat anti-mouse $\mathrm{IgG}$ antibody (Santa Cruz Biotechnology) diluted 1:100 in PBS. Then, samples were washed twice, resuspended in $500 \mathrm{~mL}$ PBS and stained with PI (50 mg/mL in PBS) for $15 \mathrm{~min}$ at RT in the dark before flow cytometric analysis. Positive controls were prepared by incubating samples for $1 \mathrm{~h}$ at RT with $\mathrm{H}_{2} \mathrm{O}_{2}(2 \mathrm{mM})$ and $\mathrm{FeCl} 24 \mathrm{H} 2 \mathrm{O}(1 \mathrm{mM})$ in a final volume of $200 \mathrm{lL}$ of PBS, as previously described, before fixation procedure (27).

\section{Identification of leukocyte subsets}

Leukocyte subsets were determined by flow cytometry, which allowed calculating percentages even at a very low cell concentration, by acquiring 10,000 events or more in each sample testing. On the forward scatter (FSC) vs. side scatter (SSC) flow cytometric dot plot, round cells are not fully distinguishable from spermatozoa (28), so 
it was impossible to accurately determine the percentage of round cells expressing CD45 by flow cytometry The concentrations of semen macrophages and activated macrophages were calculated by the flow cytometric percentages of CD45-positive (CD45+) cells expressing also CD14 (macrophages) and HLA-DR (activated macrophages) respectively. Concrete operations as follows. Cell suspensions $(70 \mu \mathrm{L})$ were incubated for $30 \mathrm{~min}$ at room temperature (RT) with $10 \mu \mathrm{L}$ of the following monoclonal antibodies (mAb): (I) ECD-conjugated anti-CD45 mAb diluted in a buffer-containing $0.2 \%$ bovine serum albumin (BSA) (Beckman Coulter, Rome, Italy), (II) fluorescein isothiocyanate (FITC)-conjugated anti-CD14 mAb diluted in a buffer containing 5\% BSA (Gen-probe, Diaclone, Pantec S.r.l., Turin, Italy), and (III) phycoerythrin (PE)conjugated anti-HLA-DR mAb diluted in a buffer containing 1\% BSA (Gen-probe, Diaclone, Pantec S.r.l.). After two washes in PBS (400 g for $7 \mathrm{~min}$ ), cell suspensions were analyzed within a few minutes at a flow cytometer (Beckman Coulter's Epics XL-MCL; Beckman Coulter, Inc., Fullerton, CA, USA) equipped with a $15 \mathrm{~mW}$ argonion laser for excitation. For each sample, 10,000 events were recorded at a flow rate of 200-300 cells/s. The FITC, PE and ECD fluorescence were measured in the FL-1, FL-2 and FL-3 channel, respectively. At the ECD fluorescence (y-axis) vs. SSC (x-axis) plot, events in the lower-left corner, representing debris and CD45-negative cells (spermatozoa and germ-line round cells), were excluded from the analysis, whereas events in the upper quadrant represented CD45+ cells (leukocytes). The whole gated $\mathrm{CD} 45+$ population was further analyzed on the FL-1 channel to obtain the percentage of CD45+ cells exhibiting FITC labeling of CD14 (monocytes/macrophages). Finally, CD14-positive (CD14+) cells were analyzed on the FL-2 channel to calculate the proportion of monocytes/macrophages also exhibiting the red PE fluorescence of HLA-DR antigens (activated macrophages). The percentages of labeled cells were immediately evaluated, using the flow cytometer System II Version 3.0 software (Beckman Coulter, Inc.).

\section{DNA fragmentation index (DFI)}

Using the SpermFunc ${ }^{\mathrm{TM}}$ DNAf kit (BRED Life Science, Shenzhen, China), Sperm Chromatin dispersion (SCD) test was performed to measure the DNA fragmentation in native and separated semen with density gradient centrifugation (DGC). Gelled aliquots of low-melting-point agarose in the kit were provided for semen sample processing in Eppendorf tubes. Eppendorf tubes were placed in a water bath at $80{ }^{\circ} \mathrm{C}$ for $20 \mathrm{~min}$ to melt the agarose and then transferred to a water bath at $37^{\circ} \mathrm{C}$ for $5 \mathrm{~min}$ for temperature equilibration. A total of $60 \mu \mathrm{L}$ semen collected was added to and mixed with the agarose in the Eppendorf tubes. Then, $30 \mu \mathrm{L}$ of the semen-agarose mixture was pipetted onto pre-coated slides in the kit, and a $22 \mathrm{~mm} \times$ $22 \mathrm{~mm}$ coverslip was covered on it. The slides were placed on a cold plate in the refrigerator $\left(4^{\circ} \mathrm{C}\right)$ for $5 \mathrm{~min}$, allowing the agarose to produce microgel in which the sperm cells were embedded. The coverslips were gently removed, and the slides were immediately immersed horizontally in solution A and incubated for $7 \mathrm{~min}$, then in solution B for $25 \mathrm{~min}$. After being washed for $5 \mathrm{~min}$ in a tray with abundant distilled water, the slides were dehydrated in gradient concentrations of ethanol $(70 \%, 90 \%, 100 \%$; respectively) each for $2 \mathrm{~min}$, air-dried, and stored at room temperature in opaque closed boxes.

Staining for bright-field microscopy was performed using a solution of Wright's staining solution (BRED Life Science, Shenzhen, China) mixed with phosphate buffer solution (BRED Life Science, Shenzhen, China) (1:2) for 15 min under continuous airflow. Then, the slides were washed in running water for $10 \mathrm{~s}$ and allowed to dry. Strong staining was recommended to allow the periphery of the dispersed DNA loop halos more visible. A minimum of 500 spermatozoa should be counted on each sample under the $100 \times$ magnification.

Normal spermatic DNA presents large radiate halos and damaged spermatic DNA presents no or small halos. The small halos mean the thickness of the halo on one side was less than the $1 / 3$ diameter of the head's thinnest part. The rate of sperm DNA fragmentation (\%) = number of sperms with fragmented DNA/the total number of sperms $\times 100 \%$; $<25 \%$ was considered normal.

\section{Statistical analysis}

Statistical analysis was performed using SPSS 19.0 software. Non-normal data were expressed as median and interinterquartile range and analyzed using non-parametric statistical analysis. Spearman correlation coefficient was used to evaluate the correlation between variables. The Wilcoxon rank-sum test was used for comparison of categorical data between two groups. Kruskall Wallis H test was performed for comparison between multi-groups. Multiple regression analysis was used to evaluate the independent contribution of semen and clinical parameters 
Table 1 Clinical data and semen parameters of males with genital tract infection $(\mathrm{n}=108)$

\begin{tabular}{lc}
\hline Variable & Median [range] or $\mathrm{n}(\%)$ \\
\hline Age (year) & $36[31-41]$ \\
Smoking & $53(49.1)$ \\
Abstinence time $(\mathrm{d})$ & $4[3-6]$ \\
Semen volume $(\mathrm{mL})$ & $3.5[2.5-4.6]$ \\
Semen pH & $7.5[7.5-7.9]$ \\
Sperm concentration $\left(\times 10^{6} / \mathrm{mL}\right)$ & $35[13.6-76]$ \\
Total motile sperm $\left(\times 10^{6} / \mathrm{mL}\right)$ & $52.0[17-150.00]$ \\
Oval-headed sperm $(\%)$ & $7[3-14]$ \\
SCD sperm $(\%)$ & $18[9-35]$ \\
CD14+ cells $\left(\times 10^{6} / \mathrm{mL}\right)$ & $0.06[0.02-0.90]$ \\
HLA-DR+ cells $\left(\times 10^{6} / \mathrm{mL}\right)$ & $0.02[0.00-0.11]$ \\
$8-O H d G$ sperm $(\%)$ & $6.3[2.2-14.0]$ \\
CD45+ cells $\left(\times 10^{6} / \mathrm{mL}\right)$ & $0.77[0.30-1.68]$ \\
\hline
\end{tabular}

for predicting the aberrant expression of sperm 8-OHdG. Significant level: $\mathrm{a}=0.05$.

\section{Results}

\section{Analysis of leukocyte subsets and semen parameters in semen}

Table 1 shows semen parameters of 108 ejaculates from male partners of subfertile couples asymptomatic for a genital tract infection. The recruited participants ranged in age from 31 to 41 years old with a median age of 36 years. Sperm concentration in all sample ranged from 13.6 to $76.0 \times 10^{6} / \mathrm{mL}$ with a median concentration of $35 \times 10^{6} / \mathrm{mL}$. The median levels (ranges) of the other relevant parameters (total motile sperm, oval- headed sperm, SCD+ sperm, CD14+ cells and 8-OHdG+ sperm) are 52.0 (17-150.00) $\times 10 \% \mathrm{~mL}, 7 \%(3-14 \%), 18 \%(9-35 \%), 0.06(0.02-$ $0.90) \times 10^{6} / \mathrm{mL}$, and $6.3 \%(2.2-14.0 \%)$, respectively, see Table 1.

\section{Semen parameters described according to groups divided by the different concentration of $C D 45+c e l l$}

There was no significant correlation between the concentrations of different leukocyte subgroups and the percentage of $8-\mathrm{OHdG}$-positive $(8-\mathrm{OHdG}+)$ cells.
According to the concentration (quartile value) of CD45+ cell in semen, 108 cases were divided into 4 groups [I: $0.3 \times 10^{6} / \mathrm{mL}$; II $(0.3-0.7) \times 10^{6} / \mathrm{mL}$; III: $(0.7-1.5) \times 10^{6} / \mathrm{mL}$; IV: $\left.>1.5 \times 10^{6} / \mathrm{mL}\right]$, intergroup comparison was performed. There were no statistical significant differences on sperm DNA fragment rate and 8-OHdG level among different groups. Although no statistical difference on sperm morphology was found between III and IV, significant difference existed between I and II. The concentration of CD14+ and HLA-DR-positive (HLA-DR+) cells significantly increased along with the concentration of CD45 + cell $(\mathrm{P}<0.01)$, and CD45 + cell concentration was highly correlated with the levels of CD14+ and HLA-DR+ cell $(\mathrm{r}=0.85, \mathrm{P}<0.01 ; \mathrm{r}=0.77, \mathrm{P}<0.01)$, see Table 2 .

\section{Correlation between sperm DNA fragmentation rate and sperm 8-OHdG semen parameters}

According to the median percentage of $8-\mathrm{OHdG}+$ sperm, 108 specimens were divided into two groups. High-level of 8-OHdG was associated with increased sperm DNA fragment rate and decreased sperm concentration $(\mathrm{P}<0.01)$, but not with the percentage of forward-moving sperm or normal morphology sperm, these results were consistent with our expected, see Table 3.

\section{Correlation of semen parameters with the percentage of 8-OHdG+ or SCD-positive (SCD+) sperm, respectively}

The two groups had different concentration of leukocyte, and the $8-\mathrm{OHdG}$ sperm rate was positively correlated with the sperm DNA fragment percentage $(\mathrm{r}=0.42, \mathrm{P}<0.01)$, but negatively correlated with the sperm concentration and the total number of active sperm $(\mathrm{r}=-0.32, \mathrm{P}<0.01$; $\mathrm{r}=-0.39, \mathrm{P}<0.01)$. The percentage of $8-\mathrm{OHdG}+$ sperm was not associated with age, percentage of forward-moving sperm, the percentage of normal morphology sperm, and concentrations of different leukocyte subsets. The percentage of sperm DNA fragments correlated with the normal morphology sperm, the correlation coefficients (all had $\mathrm{P}<0.01$ ) were $-0.43,-0.30$ and -0.28 respectively, see Table 4.

\section{Multivariate correlation analysis of $8-O H d G+$ sperm percentage}

Multiple regression analysis showed that there was a significant correlation between sperm concentration and 
Table 2 Comparison of general clinical data of patients with different concentrations of CD45 cells

\begin{tabular}{|c|c|c|c|c|c|}
\hline Variable & I & II & III & IV & $\mathrm{P}$ \\
\hline Abstinence time (d) & $3.8(3.0-4.8)$ & $3.9(3.1-4.9)$ & $4.8(3.1-4.9)$ & $5.0(3.1-5.1)$ & 0.16 \\
\hline Semen volume $(\mathrm{mL})$ & $3.28(2.8-5.1)$ & $3.3(2.5-4.8)$ & $3.6(2.6-5.9)$ & $3.7(2.2-5.0)$ & 0.80 \\
\hline Semen $\mathrm{pH}$ & $7.5(7.5-7.8)$ & $7.6(7.6-7.9)$ & $7.5(7.5-7.7)$ & $7.8(7.7-7.9)$ & 0.09 \\
\hline Progressively motile sperm (\%) & $50.5(37.5-60.0)$ & $36.0(25.8-51.5)$ & $50.0(39.5-63.3)$ & $52.2(37.0-61.5)$ & 0.10 \\
\hline Total motile sperm $\left(\times 10^{6} / \mathrm{mL}\right)$ & $46.8(20.8-103.9)$ & $46.9(4.5-80.0)$ & $77.5(12.3-192.7)$ & $77.6(16.0-156.8)$ & 0.08 \\
\hline Oval-headed sperm (\%) & $11.8(3.9-21.5)^{\mathrm{i}}$ & $3.0(2.5-6.1)^{\mathrm{ii}}$ & $6.8(6.0-15.0)$ & $7.9(4.5-15.5)$ & 0.03 \\
\hline SCD+ sperm (\%) & $15.6(8.5-35.5)$ & $23.8(17.2-40.0)$ & $23.5(18.0-36.6)$ & $18.2(6.8-33.5)$ & 0.31 \\
\hline HLA-DR+ cells $\left(\times 10^{6} / \mathrm{mL}\right)$ & $0.01(0.01-0.02)^{\mathrm{iv}}$ & $0.00(0.00-0.03)^{\mathrm{iv}}$ & $0.02(0.01-0.15)^{v}$ & $0.13(0.06-0.50)$ & $<0.01$ \\
\hline
\end{tabular}

Values are expressed as median (interquartile range); through, $\mathrm{P}<0.05$ at adjusted post hoc analysis: ${ }^{\text {, }}$, compared to quartile II; ii , compared to quartile IV; ${ }^{\text {iii }}$, compared to all; ${ }^{\text {iv }}$, compared to quartiles III, IV; ${ }^{\mathrm{v}}$, compared to quartile IV.

Table 3 Comparison of clinical data and routine parameters between two groups of high or low percentage of 8-OHdG

\begin{tabular}{|c|c|c|c|}
\hline Variable & \multicolumn{2}{|c|}{$8-\mathrm{OHdG}+35.5(32.00-41.0)$} & $\mathrm{P}$ \\
\hline Age (year) & $35.6(31.3-40.0)$ & 35.5 (32.00-41.0) & 0.55 \\
\hline Smoking, n (\%) & $28(46.3)$ & $31(62.0)$ & 0.53 \\
\hline Abstinence time (d) & $4.2(3.2-5.3)$ & $4.1(3.3-5.2)$ & 0.58 \\
\hline Semen $\mathrm{pH}$ & $7.5(7.5-7.9)$ & $7.6(7.6-7.9)$ & 0.89 \\
\hline Sperm concentration $\left(\times 10^{6} / \mathrm{mL}\right)$ & $52.3(28.6-105.7)$ & $31.0(8.9-56.0)$ & 0.008 \\
\hline Progressively motile sperm (\%) & $50.0(31.0-56.0)$ & $51.6(39.3-62.5)$ & 0.36 \\
\hline Total motile sperm $\left(\times 10^{6}\right)^{\star}$ & $65.8(23.0-160.0)$ & $39.2(9.0-109.8)$ & 0.03 \\
\hline 8-OHdG+ sperm (\%) & $2.3(1.1-3.8)$ & $12.8(11.5-25.9)$ & $<0.01$ \\
\hline HLA-DR+ cells $\left(\times 10^{6} / \mathrm{mL}\right)$ & $0.02(0.02-0.12)$ & $0.03(0.01-0.08)$ & 0.51 \\
\hline CD $45+$ cells $\left(\times 10^{6} / \mathrm{mL}\right)$ & $0.82(0.38-1.58)$ & $0.85(0.30-1.60)$ & 0.96 \\
\hline
\end{tabular}

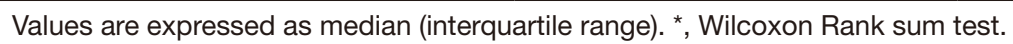


Table 4 Correlation of semen parameters with the percentage of $8-\mathrm{OHdG}+$ or SCD+ sperm, respectively

\begin{tabular}{lccccc}
\hline \multirow{2}{*}{ Parameter } & \multicolumn{2}{c}{$8-\mathrm{OHdG}+$ sperm } & & \multicolumn{2}{c}{ SCD+ sperm } \\
\cline { 2 - 3 } \cline { 6 - 7 } & $\mathrm{r}$ & $\mathrm{P}$ & & $\mathrm{r}$ & $\mathrm{P}$ \\
\hline Sperm concentration & -0.32 & $<0.01$ & & -0.43 & $<0.01$ \\
Progressively motile sperm & -0.02 & 0.56 & & -0.30 & $<0.01$ \\
Total motile sperm & -0.39 & $<0.01$ & & -0.42 & $<0.01$ \\
Oval-headed sperm & 0.03 & 0.69 & & -0.28 & $<0.01$ \\
SCD+ sperm & 0.42 & $<0.01$ & & - & - \\
CD45+ cells & 0.05 & 0.60 & & 0.05 & 0.67 \\
CD14+ cells & 0.12 & 0.15 & & 0.26 & 0.23 \\
HLA-DR+ cells & 0.02 & 0.90 & 0.005 & 0.85 \\
\hline
\end{tabular}

Table 5 multivariate correlation analysis of $8-\mathrm{OHdG}+$ sperm percentage

\begin{tabular}{lcc}
\hline Correlated factor & $\mathrm{B}$ & $\mathrm{P}$ \\
\hline Sperm concentration & -0.30 & $<0.01$ \\
SCD+ sperm & 0.18 & 0.06 \\
Age & -0.29 & 0.36 \\
Smoking & 0.06 & 0.42 \\
Abstinence & -0.28 & 0.49 \\
\hline
\end{tabular}

percentage of sperm DNA fragments after adjusting for age, abstinence time and smoking factors $(\mathrm{r}=-0.30, \mathrm{P}<0.01$; $\mathrm{r}=0.18, \mathrm{P}=0.06$ ), see Table 5 .

\section{Discussion}

Genital tract infection, usually presenting as nongonococcal urethritis, is often caused by mycoplasma and chlamydia. Most sufferers with infection-induced infertility present no symptoms $(29,30)$. According to epidemiological analyses, in Asia, the prevalence of genital tract infection by mycoplasma is high in Iran, followed by India (6.0\%) and low in Vietnam (0.8\%); In Europe, this prevalence stays at $1.1-7.1 \%(31,32)$. But in China, it reaches $17.7 \%$ and even higher in people who do not use condoms during intercourse for more than three months or have other sexually transmitted diseases (STD) $(33,34)$. Another research concludes that this infection can prolong sperm liquefaction and lower sperm quality, two processes leading to male infertility (35).

The influence of semen leukocytes on the quality of semen has been controversial. Through a lot of research, the conclusions are different $(2,3)$. It is reported in the literature that leukocytes have adverse effects on sperm parameters, sperm function and male infertility, compared with normal fertility group (3-7). The number of leukocytes in infertile males increased significantly. Studies by Arata de Bellabarba et al. (36) have shown that semen leukocytosis leads to a decrease in semen volume, decreased sperm density, viability, fertilization ability, and can also lead to sperm cell chromatin changes, sperm DNA damage, immature spermatogenic cells and abnormal sperm counts. An article published in the authoritative journal Fertility \& Sterility of Reproductive Biology states that when the number of leukocytes in semen is less than $1 \times 10^{6} / \mathrm{mL}$, leukocytes can improve the fertility of sperm and the clinical pregnancy rate of in vitro fertilization (IVF); once the number of leukocytes in semen is greater than $1 \times 10^{6} / \mathrm{mL}$, that is, the IVF clinical pregnancy rate of patients with LCS is significantly reduced (37). Several studies have shown that the use of leukocyte-specific antibodies such as CD45 to detect semen leukocyte level, the results show that CD45 + cell concentration and sperm parameters have no significant correlation in semen of infertile men with asymptomatic genital tract infection (38-41), these are in line with the recent research results of Liu (25). In this study, macrophage and activated macrophage of leukocyte subsets were detected based on surface biomarker CD14 and HLA-DR antigen, both their concentrations had no correlations with semen routine parameters (Table 2). This was inconsistent with the result reported by Pelliccione et al. (42), their research gained a negative correlation between semen routine parameters and HLA-DR+ cells. It may be necessary to increase the sample size to further reveal the relationship between activated macrophages and semen quality. The potential impact of semen leukocytes on male fertility remains unclear, but in many literatures it reported that elevated leukocytes are indeed associated with low fertilization rate and low cleavage rate during IVF or intracytoplasmic sperm injection (ICSI) (43). Simultaneously, different subsets of semen leukocytes are associated with IVF or ICSI and natural pregnancy abortion (44). The concentration of CD45 + cell was negatively correlated with the fertilization rate of MII eggs (45).

About $95 \%$ of semen leukocytes are neutrophils and macrophages, which produce ROS to induce oxidative stress, induce apoptosis and lead to decreased sperm count 
and damaged sperm. The damage of plasma membrane reduces sperm motility and fertilization, leading to male infertility. The possible mechanism is that the mitochondrial sheath located in the middle of sperm is the energy supply center for sperm movement. When leukocytes in semen increase, the release of ROS can cause lipid peroxidation of unsaturated fatty acids in the inner and outer membranes of sperm mitochondria, ATP synthesis reduced, ultimately affecting semen quality, leads to decreased sperm acrosome reaction and egg cell fusion. Recently, studies have shown that sperm DNA fragments are more easily detected in semen of patients with LCS, and LCS can induce sperm DNA damage and has a cascade effect $(4,46)$. Excessive generation of reactive oxygen species can stimulate the expression of $8-\mathrm{OHdG}$, and $8-\mathrm{OHdG}$, as an oxidative adduct, is a sensitive indicator of the degree of peroxidation and ROS formation (30). 8-OHdG as a biomarker of DNA damage, expresses at the single sperm cell level can be detected by immunofluorescence staining and flow cytometry (47). The result of this study shows that $8-\mathrm{OHdG}$ level is closely related to sperm DNA damage measured by chromatin diffusion method. Semen 8-OHdG immunofluorescence expression and sperm DNA fragmentation associated with decreased sperm quality, but not related to differential leukocyte subsets, suggesting that oxidative stress-induced sperm DNA damage may be related to sperm structural function impairment, and supporting hypothesis that sperm DNA damage is related to errors that occur during spermatogenesis (Table 3).

Aitken et al. (48) showed that less chromatin amination during spermatogenesis resulted in the formation of more fragile sperm and eventually formed defective sperm in the testes. Exposure to ROS enhanced oxidative damage and promotes mitochondrial apoptosis in sperm, increased the percentage of DNA fragments in defective sperm, and 8-OHdG expression was associated with sperm DNA fragmentation and low sperm concentration (Table 4). After adjusting age, abstinence time and smoking factors, sperm concentration and sperm fragment percentage can affect $19 \%$ of sperm 8 -OHdG changes. Oxidative stress leads to increased sperm damage rate, which is mainly reflected in the significant increase of sperm 8-OHdG level, which affects its potential fertilization ability (Table 5). Still, there are some limitations, for one is that the number of cases in this study was relatively small.

In conclusion, Chlamydia trachomatis and Ureaplasma urealyticum $(U U)$ are important pathogen of sexually transmitted diseases, which can directly or indirectly affect sperm quality. Sperm DNA damage in infertile males with asymptomatic genital tract infection is associated with decreased semen quality, but not with differential leukocyte subsets.

\section{Acknowledgments}

We thank Dr. Ya-Jun Chen, Women's Hospital of Nanjing Medical University, Nanjing Maternity and Child Health Care Hospital, Nanjing, Jiangsu 210029, China, who took part with great efforts in revising the paper in English.

Funding: None.

\section{Footnote}

Data Sharing Statement: Available at http://dx.doi. org/10.21037/apm-19-597

Conflicts of Interest: All authors have completed the ICMJE uniform disclosure form (available at http://dx.doi. org/10.21037/apm-19-597). The authors have no conflicts of interest to declare.

Ethical Statement: The authors are accountable for all aspects of the work in ensuring that questions related to the accuracy or integrity of any part of the work are appropriately investigated and resolved. The study was approved by the Ethics Committee of Women's Hospital of Nanjing Medical University (No. 20180332) and conducted in accordance with the Declaration of Helsinki (as revised in 2013). All the patients provided the written informed consent.

Open Access Statement: This is an Open Access article distributed in accordance with the Creative Commons Attribution-NonCommercial-NoDerivs 4.0 International License (CC BY-NC-ND 4.0), which permits the noncommercial replication and distribution of the article with the strict proviso that no changes or edits are made and the original work is properly cited (including links to both the formal publication through the relevant DOI and the license). See: https://creativecommons.org/licenses/by-nc-nd/4.0/.

\section{References}

1. Moubasher A, Sayed H, Mosaad E, et al. Impact of Leukocytospermia on Sperm Dynamic Motility Parameters, DNA and Chromosomal Integrity. Cent 
European J Urol 2018;71:470-5.

2. Brunner RJ, Demeter JH, Sindhwani P. Review of Guidelines for the Evaluation and Treatment of Leukocytospermia in Male Infertility. World J Mens Health 2019;37:128-37.

3. Bachir BG, Jarvi K. Infectious, inflammatory, and immunologic conditions resulting in male infertility. Urol Clin North Am 2014;41:67-81.

4. Khodamoradi K, Kuchakulla M, Narasimman M, et al. Laboratory and clinical management of leukocytospermia and hematospermia: a review. Ther Adv Reprod Health 2020;14:2633494120922511.

5. Castellini C, D'Andrea S, Martorella A, et al. Relationship Between Leukocytospermia, Reproductive Potential After Assisted Reproductive Technology, and Sperm Parameters: A Systematic Review and Meta-Analysis of Case-Control Studies. Andrology 2020;8:125-35.

6. Micheli L, Collodel G, Cerretani D, et al. Relationships between Ghrelin and Obestatin with MDA, Proinflammatory Cytokines, GSH/GSSG Ratio, Catalase Activity, and Semen Parameters in Infertile Patients with Leukocytospermia and Varicocele. Oxid Med Cell Longev 2019;2019:7261842.

7. Sandoval JS, Raburn D, Muasher S. Leukocytospermia: Overview of diagnosis, implications, and management of a controversial finding. Middle East FertilSoc J 2013;18:129-34.

8. Saxena P, Soni R, Randhawa VS, et al. Can Seminal IL-8 Level Be Used as a Marker of Leukocytospermia and Does It Have Any Correlation with Semen Parameters in Infertile Couples? J Obstet Gynaecol India 2019;69:451-6.

9. Pentyala S, Lee J, Annam S, et al. Current perspectives on pyospermia: A review. Asian Journal of Andrology 2007;9:593-600.

10. Jung JH, Kim MH, Kim J, et al. Treatment of Leukocytospermia in Male Infertility: A Systematic Review. World J Mens Health 2016;34:165-72.

11. Li J, Liu RZ. Progresss in Leukocytospermia Research. Zhonghua Nan Ke Xue 2006;12:730-2.

12. Eggert-Kruse W, Zimmermann K, Geissler W, et al. Clinical relevance of polymorphonuclear (PMN) elastase determination in semen and serum during in fertility investigation. Int J Androl 2009;32:317-29.

13. Lobascio AM, De Felici M, Anibaldi M, et al. Involvement of seminal leukocytes, reactive oxygen species, and sperm mitochondrial membrane potential in the DNA damage of the human spermatozoa. Andrology 2015;3:265-70.

14. Agarwal A, Tvrda E, Sharma R. Relationship amongst teratozoospermia, seminal oxidative stress and male infertility. Reprod Biol Endocrinol 2014;12:45.

15. Kocpinar EF, Baltaci NG, Ceylan H, et al. Effect of a Prolonged Dietary Iron Intake on the Gene Expression and Activity of the Testicular Antioxidant Defense System in Rats. Biol Trace Elem Res 2020;195:135-41.

16. Ribas-Maynou J, Yeste M. Oxidative Stress in Male Infertility: Causes, Effects in Assisted Reproductive Techniques, and Protective Support of Antioxidants. Biology (Basel) 2020;9:77.

17. Guo JQ, Xu WM. Effect of reactive oxygen species on the sperm and its generation. The Chinese Journal of Human Sexuality 2017;26:88-90.

18. Gong QQ,Zhang CJ. Reactive oxygen species and protection against sperm DNA damage. Chinese Journal of Human Sexualit 2012;21:3-6.

19. Taken K, Alp HH, Eryilmaz R, et al. Oxidative DNA Damage to Sperm Cells and Peripheral Blood Leukocytes in Infertile Men. Med Sci Monit 2016;22:4289-96.

20. Wright C, Milne S, Leeson H. Sperm DNA damage caused by oxidative stress: modifiable clinical, lifestyle and nutritional factors in male infertility. Reprod Biomed Online 2014;28:684-703.

21. Gao RX, Yao ZH, Shao HX. Research progress on the correlation between urinary 8-ohdg and diabetic atherosclerosis. Tian Jin Medical Journal 2009;37:809-11.

22. Graille $M$, Wild $P$, Sauvain JJ, et al. Urinary $8-O H d G$ as a Biomarker for Oxidative Stress: A Systematic Literature Review and Meta-Analysis. Int J Mol Sci 2020;21:E3743.

23. Breton CV, Kile ML, Catalano PJ, et al. GSTM1 and APE1 genotypes affect arsenic-induced oxidative stress: a repeated measures study. Environ Health 2007;6:39-45.

24. Wei CL, Y Hong L, Min C, et al. Progress on the Detection Techniques for DNA damage of Sperm. Progress in Modern Biomedicine 2015;15:3597-600.

25. Liu XC, Chen GS, He XL. Sperm DNA damage is not related to seminal leukocyte subsets in infertile males with asymptomatic genital tract infection. National Journal of Andrology 2018;24:45-9.

26. Ricci G, Presani G, Guaschino S, et al. Leukocyte detection in human semen using flow cytometry. Hum Reprod 2000;15:1329-37.

27. Kasai H. Analysis of a form of oxidative DNA damage, 8-hydroxy-2'-deoxyguanosine, as a marker of cellular oxidative stress during carcinogenesis. Mutat Res 1997;387:147-63.

28. Cooper TG, Noonan E, von Eckardstein S, et al. World Health Organization reference values for human semen 
characteristics. Hum Reprod Update 2010;16:231-45.

29. Barbonetti A, Vassallo MRC, Costanzo M, et al. Involvement of cannabinoid receptor- 1 activation in mitochondrial depolarizing effect of lipopolysaccharide in human spermatozoa. Andrology 2014;2:502-9.

30. Herwig R, Knoll C, Planyavsky M, et al. Proteomic analysis of seminal plasma from infertile patients with oligoasthenoteratozoospermia due to oxidative stress and comparison with fertile volunteers. Fertil Steril 2013;100:355-66.e2.

31. Zhang YQ. Correlation analysis between semen quality and the levels of seminal IL-6 and IL-8 in Chlamydia trachomatis infection-caused male infertility. Chinese Journal of Andrology 2017;31:46-50.

32. European Centre for Disease Prevention and Control. Sexually transmitted infections in Europe 2013. Stockholm: ECDC; 2015.

33. Soni S, Alexander S, Verlander N, et al. The prevalence of urethral and rectal Mycoplasma genitalium and its associations in men who have sex with men attending a genitourinary medicine clinic. Sex Transm Infect 2010;86:21-4.

34. Zhang JJ, Zhao GL, Wang F, et al. Molecular epidemiology of genital Chlamydia trachomatis infection in Shenzhen, China. Sex Transm Infect 2012;88:272-7.

35. Miron ND, Socolov D, Mareş M, et al. Bacteriological agents which play a role in the development of infertility. Acta Microbiol Immunol Hung 2013;60:41-53.

36. Arata de Bellabarba G, Tortolero I, Villarroel V, et al. Nonsperm cells in human semen and their relationship with semen parameters. Arch Androl 2000;45:131-6.

37. Barraud-Lange V, Pont JC, Ziyyat A, et al. Seminal leukocytes are Good Samaritans for spermatozoa. Fertil Steril 2011;96:1315-9.

38. Vivian Taís Fernandes C, Anderson M, Gilberto da Costa F, et al. Evaluation of seminal parameters in the indication of in vitro fertilization or intracytoplasmic sperm injection in the treatment of the male factor fertility problem. Reprod Clim 2010;25:104-9.

39. Ricci G, Granzotto M, Luppi S, et al. Effect of seminal leukocytes on in vitro fertilization and intracytoplasmic sperm injection outcomes. Fertil Steril 2015;104:87-93.

40. Homa ST, Vassiliou AM, Stone J, et al. A Comparison Between Two Assays for Measuring Seminal Oxidative Stress and Their Relationship With Sperm DNA Fragmentation and Semen Parameters. Genes (Basel) 2019;19;10:236.

41. Su CX, Wang L, Wang RZ, et al. Clinical study on the effect of Leukocytospermia on sperm quality in infertile men. Chinese Journal of Laboratory Diagnosis 2015;19:665-6.

42. Pelliccione F, D'Angeli A, Cinque B, et al. Activation of the immune system and sperm DNA fragmentation are associated with idiopathic oligoasthenoteratospermia in men with couple subfertility. Fertil Steril 2011,95:2676-9.e1.

43. Seshadri S, Flanagan B, Vince G, et al. Leucocyte subpopulations in the seminal plasma and their effects on fertillisation rates in an IVF cycle. Andrologia 2012,44:396-400.

44. Tomlinson MJ, Barratt CL, Cooke ID. Prospective study of leukocytes and leukocyte subpopulations in semen suggests they are not a cause of male infertility. Fertil Steril 1993;60:1069-75.

45. Durairajanayagam D. Lifestyle Causes of Male Infertility. Arab J Urol 2018;16:10-20.

46. Pascarelli NA, Fioravanti A, Moretti E, et al. The effects in vitro of TNF- $\alpha$ and its antagonist 'etanercept' on ejaculated human sperm. Reprod Fertil Dev 2017;29:1169-77.

47. Agarwal A, Esteves SC. Varicocele and male infertility: current concepts and future perspectives. Asian J Androl 2016;18:161-2.

48. Aitken RJ, Smith TB, Jobling MS, et al. Oxidative stress and male reproductive health. Asian J Androl 2014;16:31-8.
Cite this article as: Liu KS, Mao XD, Pan F, Chen YJ. Application of leukocyte subsets and sperm DNA fragment rate in infertile men with asymptomatic infection of genital tract. Ann Palliat Med 2021;10(2):1021-1030. doi: 10.21037/apm-19-597 